\title{
PLANEJAMENTO PASTORAL: aplicação da metodologia participativa
}

\author{
Matheus Lincoln B. Santos \\ Graduando em Engenharia Elétrica e Telecomunicações pela PUCPR e em Licenciatura em \\ Física pela Universidade Federal do Paraná, Auxiliar de agente de Pastoral da PUCPR, Câmpus \\ Curitiba, Curitiba, PR - Brasil, e-mail: matheus.lincoln@ pucpr.br
}

\section{Introdução}

Toda vez que ouvimos falar em planejamento, em busca de metas e resultados, em missão e visão, logo nos vem à idéia de uma grande empresa, de um negócio ou um projeto que precisa ser executado. Mas, será que é possível aplicarmos as técnicas de planejamento à prática pastoral? Uma luz para esta questão vem nas palavras do próprio Cristo a seus apóstolos:

\begin{abstract}
Pois, qual de vós, pretendendo construir uma torre, não se assenta primeiro para calcular a despesa e verificar se tem os meios para concluí-la? Para não suceder que, tendo lançado os alicerces e não a podendo acabar, todos os que a virem zombem dele, dizendo: Este homem começou a construir e não pôde acabar. (Lc 14).
\end{abstract}

Certamente, o processo de evangelização é conduzido pelo Espírito de Deus e ganha constantemente novos métodos, novas formas, buscando atualizar-se no tempo e no espaço. O conteúdo que segue deseja ser mais uma proposta, entre as tantas que já existem, no horizonte das metodologias de pastoral. Assim, o objetivo central desse texto é fazer um breve relato sobre técnicas já aplicadas a outros segmentos como o planejamento participativo e a análise SWOT e a possibilidade de sua aplicação no planejamento da prática pastoral. 


\section{Conceitos básicos}

Para que possamos iniciar um processo de planejamento temos que estar familiarizados com alguns termos da área. O primeiro deles é a própria idéia de "planejamento". Planejar, segundo Agenor Brighenti (1988), é deixar de improvisar, é projetar o futuro. Para Danilo Gandin, planejar é "definir o necessário. É realizá-lo sem que o imediato o sufoque" (GANDIN, 1994, p. 98). Ao ato de se planejar damos o nome de planejamento. Quando planejamos algo adotamos uma linha de direção a ser seguida, prevemos alguns passos e criamos meios de avaliar se estamos ou não atingindo os objetivos esperados; é, portanto, algo que permeia o antes, o durante e o depois de qualquer ação ou projeto. Desta maneira, damos início ao processo de construção do ambiente ao nosso redor com as características que foram previamente estabelecidas, definindo sempre qual o próximo objetivo a ser alcançado. Esta ação torna nossas atividades mais claras, eficientes e eficazes, além de dar possibilidade de ela ser realmente transformadora.

Existem inúmeras formas de se planejar, assumidas de modos diversificados para os diversos setores da sociedade. Para a atuação no âmbito de pastoral, um formato que parece ser mais adequado é o do planejamento participativo (PP). Esta metodologia teve sua origem nas ciências sociais e é amplamente aplicada a prefeituras, ONGs e demais empresas do terceiro setor. No processo do PP todas as ações giram em torno dos destinatários e são eles mesmos que ajudam a construí-lo. A comunidade integra o PP dando suas características a ele, enquanto ele dá vez e voz a ela. No PP aplicam-se ainda o discernimento comunitário e a decisão partilhada onde todos trabalham na sua elaboração, aplicação e avaliação. Essa metodologia cria uma ação desconcentrada, quebrando o aumento do poder e dando autonomia a seus colaboradores.

Tendo abordado os conceitos de planejamento e planejamento participativo, é oportuno agora definir rapidamente o que vem a ser a "Análise SWOT", que será uma importante ferramenta para o desenvolvimento de um plano de ação. A análise SWOT é um instrumento utilizado para a análise de cenários, dando base para o planejamento. A simplicidade na sua elaboração é um dos principais motivos de sua larga utilização. O termo SWOT vem do inglês e forma um acrônimo de Strengths (forças), Weaknesses (Fraquezas), Opportunities (Oportunidades) e Threats (Ameaças). O modelo SWOT é bastante indicado por analisar qualquer tipo de ambiente, pois faz um cruzamento 
entre o ambiente interno e externo dando uma boa visão da realidade em que estamos inseridos. No decorrer deste relato pastoral detalharemos um pouco melhor a metodologia da análise SWOT.

\section{Fundamentos do método do planejamento participativo na pastoral}

As mudanças que vem ocorrendo no mundo de hoje solicitam uma Igreja mais dinâmica, adequada à nova realidade em que ela está inserida. Por isso ela deve planejar sua ação junto às comunidades que a compõem. Isso não significa que ela deve absorver todos os métodos empresariais e virar uma máquina de arrecadação e de desenvolvimento de projetos. Seu planejamento deve ser pautado em metodologias que permitam a participação de todos, mas estes métodos precisam ser preenchidos com seu ardor, sua história e seu magistério. Qualquer método, até mesmo o de planejamento participativo, é frio e não contagia as pessoas num primeiro momento, mas se acreditarmos na força do Espírito Santo que nos move e move a Igreja e colocarmos o amor ao trabalho pastoral inseridos na metodologia de planejamento participativo, conseguiremos envolver as pessoas e propor ações que sejam transformadoras da realidade em que estamos inseridos. Essa ação transformadora será a verdadeira expressão dessa nova evangelização que o mundo tanto nos clama. O planejamento participativo na pastoral, segundo Agenor Brighenti, deverá ser sempre co-criativo, co-participativo e co-responsável. Em seu desenvolvimento não teremos sujeitos e objetos da ação, todos serão envolvidos no planejamento, quebrando assim a dependência que temos a um pequeno grupo dominador e usando o poder para promover a autonomia dos envolvidos na ação.

\section{Metodologia de planejamento participativo em pastoral}

O processo de planejamento participativo possui uma metodologia específica que será abordada neste tópico. Sua realização possui as seguintes etapas:
a) elaboração do marco referencial
b) elaboração do diagnóstico;
c) programação;
d) avaliação. 
Estes procedimentos são de suma importância para um completo plano de ação, e em todas as etapas a comunidade deverá estar envolvida. Temos que lembrar que o método participativo não é do tipo ação-reflexão e sim reflexãoação; por isso, em cada etapa será feita uma profunda reflexão sobre a realidade antes de se agir, esta característica faz com que caiam as taxas de erros ou as perdas de foco durante a execução dos projetos ou planos de ação.

\section{Marco referencial}

O marco referencial abre a metodologia participativa, pois é nele que uma instituição, grupo ou núcleo de pastoral se compreende como um componente de uma realidade mais ampla projeta-se como portador de uma proposta sócio-política e propõem-se como realizador de um processo técnico específico de seu campo de ação (GANDIN, 1994, p. 78). Com base nessas definições, o marco referencial pode ser dividido entre marco situacional, marco doutrinal e marco operativo. Nenhum desses "marcos" funciona isoladamente, só o conjunto dos três reunidos formará um bom marco referencial para o PP. Vamos agora conhecer um pouco mais da função de cada um deles.

\section{Marco situacional}

É nesta fase do PP que compreendemos que fazemos parte do mundo, entendemos a realidade em que estamos inseridos, quais problemas e oportunidades podemos ter. Aqui, precisamos fazer uma análise sociopolítica-pastoral. Há varias técnicas utilizadas para se ter um bom marco situacional, como investigação de notícias referentes à localidade, questionários, pesquisas quali e quantitativas, análise de cenários, entre outras. Nesta fase, deve-se ter muito cuidado ao se referir à realidade, ela não deve ser mascarada para que o marco se mostre eficiente, claro e suficientemente preciso para a prática. 


\section{Marco doutrinal}

Nessa etapa a instituição assume uma proposta político-social para a realidade conhecida no marco situacional, mas, além disso, ela fundamenta essa proposta. Nele definimos o ideal de homem e de sociedade que queremos, iluminando a realidade a partir da luz da fé (BRIGHENTI, 1988, p. 35).

Quando pensamos em PP na pastoral, o marco doutrinal vem ser a Boa Nova colocada como referencial maior e passa a funcionar como um instrumento profético de transformação da realidade atual no próprio reino de Deus. Para preparar o marco, devemos ter em mãos meios que possam nos direcionar a realidade ideal, cuidando sempre para não cairmos em um fundamentalismo sufocante.

\section{Marco operativo}

O marco operativo faz com que o grupo firme o ideal de sua prática, contribuindo assim na construção da sociedade com qual se comprometeu (GANDIN, 1994, p. 82). Nele projetamos o futuro de nossa realidade e algumas formas de como atingi-la. Nele traduzimos o ideal proposto anteriormente. Um cuidado especial que devemos ter no marco operativo é o cuidado para não se perder a indentidade. Uma escola faz educação, uma indústria deve gerar lucro, uma pastoral gera vida, e assim por diante, devemos transcrever nosso foco de atuação e não devaneios que venham a desgastar nossa energia no futuro.

Para construirmos um bom marco operativo devemos transcrever os passos que daremos para sair da realidade atual e chegarmos à realidade ideal, garantindo que os passos descritos sejam viáveis e passíveis de realização.

\section{Diagnóstico}

Nesta fase do PP procuramos conhecer os pontos fracos, as oportunidades, levantar os problemas e soluções da realidade em que estamos inseridos. É fazer um estudo detalhado para fazer um juízo sobre a realidade à luz dos marcos situacional e doutrinal. O diagnóstico nada mais é que um estudo aprofundado do cenário em que estamos inseridos. Uma excelente ferramenta para se construir um bom diagnóstico é a análise SWOT. 


\section{A análise SWOT}

No esquema SWOT, fazemos uma análise que avalia as forças, fraquezas, oportunidades e ameaças, confrontando os ambientes internos e externos em que estamos inseridos.

O primeiro passo consiste em fazer uma análise do ambiente interno, avaliando assim o grupo, a instituição ou o núcleo de que fazemos parte. A análise interna concentra-se em constatar quais são as forças e fraquezas que possuímos, definindo pontos fortes e fracos de nossa equipe, de nossa estrutura, entre outros.

Depois de feita a análise interna, partimos para os fatores externos, listando as oportunidades e ameaças a nossa atuação. Fazemos uma lista dos componentes que podem somar forças a nossa atuação, aproveitando a sinergia entre elementos comuns, projetos semelhantes feitos por outras instituições ou grupos, entre outros. Listamos também os elementos que podem vir a sufocar ou a prejudicar nossa ação.

Após esta análise preliminar, colocamos os pontos levantados na matriz SWOT. Este procedimento facilitará para o próximo passo: o cruzamento dos dados.

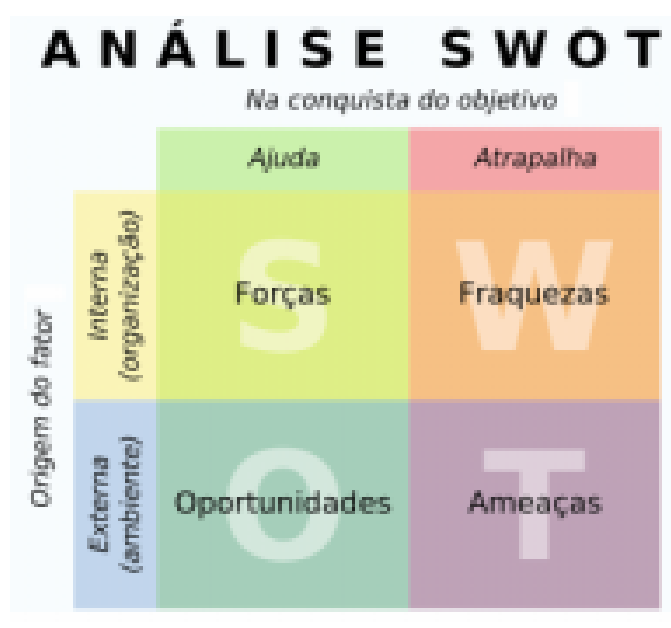

FIGURA 1 - Diagrama ou matriz SWOT 
Precisamos agora cruzar os fatores para analisarmos o cenário em que estamos inseridos. Fazemos um cruzamento entre pontos fortes (forças) e oportunidades para apontarmos caminhos mais rápidos ao sucesso de nossa ação. Cruzamos nossas forças com as ameaças verificando qual a melhor maneira de combatê-las. O terceiro cruzamento é entre nossas fraquezas com as oportunidades para verificar se há algo que possa ser prejudicado por causa disso e quais habilidades precisamos desenvolver para que não percamos nenhuma oportunidade durante nossas ações. O último cruzamento é entre fraquezas e ameaças, este é de suma importância, pois indicará as ameaças colaboram para que nossa ação não funcione. Por meio desse cruzamento definimos ações para combater os problemas e direcionamos nossa energia a ações com uma maior probabilidade de sucesso.

Esses quatro cruzamentos apontam os fatores que podem atingir nossa sobrevivência, os que garantem nossa manutenção, os que trazem crescimento e as oportunidades de desenvolvimento. Como podemos verificar na matriz de cruzamento SWOT.

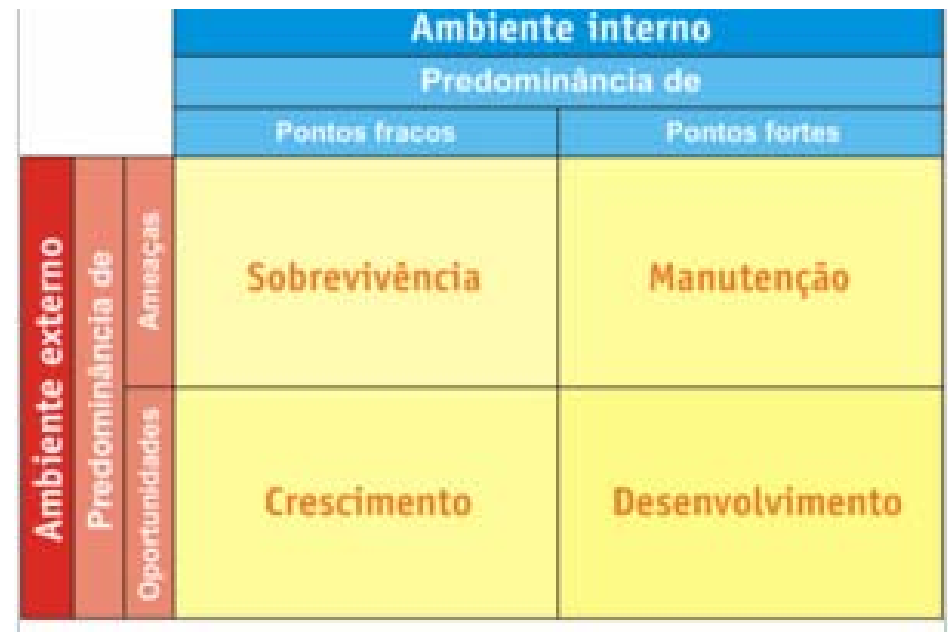

FIGURA 2 - Resultado dos cruzamentos SWOT 
Com essa análise podemos minimizar ameaças e pontos fracos e aproveitar ao máximo os fatores positivos. A análise SWOT é, portanto, uma excelente ferramenta, não só para o diagnóstico, mas para o planejamento de nossas ações.

\section{Programação}

Nesta fase entramos no processo de finalização do planejamento, aqui já temos em mãos o marco referencial e o nosso diagnóstico, basta agora definirmos os programas, projetos e ações que iremos desenvolver.

Um programa pastoral conterá uma linha de ação específica, como espiritualidade ou formação, por exemplo. Ele conterá os objetivos gerais e específicos referentes ao ponto a ser trabalhado. Cada objetivo gerará um projeto que, por fim, conterá as ações. Esse esquema de programa, projeto e ação não impede que tenhamos ações isoladas, ou projetos independentes de programas.

A construção da programação dirá os passos a serem seguidos, ela não irá definir aonde chegar, mas sim como ir até lá.

Ela deve ser focada nos recursos que temos e na situação que queremos resolver ou transformar. Seu cronograma de realização deverá ser viável. Nesta fase, as utopias passam a ser luz de ações concretas. Lembrando também que a programação não pode ser fator de engessamento ou burocratização do processo pastoral.

\section{A avaliação}

A avaliação é a etapa pós PP. Ela confrontará os objetivos alcançados com os propostos e as linhas de ação para o futuro, e assim, como o planejamento foi feito participativamente, ela deve ser participativa. Não cabe à coordenação definir o que deu certo ou não, mas a todo o grupo envolvido. A avaliação participativa é um processo de aprendizagem e de capacitação mútua (BARREIRA, M. C. R. N, 2000, p. 95).

A ferramenta principal para a avaliação participativa é a partilha, cada envolvido tem um acervo próprio de experiências coletadas durante a realização do plano. Participam dela as pessoas direta e indiretamente envolvidas na realização do programa. 
A avaliação participativa não versará somente em resultados obtidos e esperados, apesar de ser esse seu papel fundamental. Seu foco ficará no processo, avaliando o planejamento, o desenvolvimento e o resultado da ação. Avalia-se o processo e a atuação de cada um no desenrolar da ação.

\section{Conclusão}

Os temas apresentados neste relato pertinente à pastoral merecem sempre um pouco mais de atenção e de estudo na hora de se planejar. O planejamento dentro da pastoral deve tomar sempre o cuidado de não ser tecnicista; toda teoria em metodologias a ser usada deve antes passar pelo amor do pastor que conduz seu rebanho. Temos que lembrar sempre que estamos trabalhando com pessoas que carregam consigo medos, esperanças e expectativas quanto à ação pastoral. Por isso, esta deve ser gestada com o ágape do cristão e crescer à luz da fé. Nosso mundo precisa urgente de ações efetivas rumo a uma sociedade mais justa e fraterna, e essas ações não podem mais ser pensadas da noite para o dia.

\section{Referências}

A BÍBLIA de Jerusalém. 8. ed. São Paulo: Paulinas, 1981.

BARREIRA, M. C. R. N. Avaliação participativa de programas sociais. São Paulo: Veras, 2000.

BRIGHENTI, A. Metodologia para um processo de planejamento participativo. São Paulo: Paulinas, 1988.

GANDIN, D. A prática do planejamento participativo. 2. ed. Petrópolis, RJ: Vozes, 1994.

Recebido: 05/05/2008

Received: 05/05/2008

Aprovado: 07/06/2008

Approved: 06/07/2008 